\title{
Kevin Davies and the Immanency in the Statement: Interpellation's Links in Literature and Society
}

\author{
Lee Patterson
}

Department of English, Florida State University, Florida, United States

\begin{abstract}
Copyright $\subseteq 2018$ by authors, all rights reserved. Authors agree that this article remains permanently open access under
\end{abstract} the terms of the Creative Commons Attribution License 4.0 International License

\begin{abstract}
Appearing after the legacy of Language school poetry and its imitators, Kevin Davies' work in his books Comp. and The Golden Age of Paraphernalia, can be read as a development of this poetry and identified with a new current in the form: Post-Language Poetry. To support this thesis, this essay finds value and relevance in Kevin Davies' work as it explores a range of aesthetic, cultural, and political issues. After analyzing concepts of authorial presence, interpellation, site-specificity, and the limits of the performative subject, this essay places a special importance on Althusserian Interpellation to illuminate these parallel issues. The essay concludes that Davies' work both produces codes and interrogates existing codes that render subjective images of the interpellated subject.
\end{abstract}

Keywords Site-specificity, Authorial Presence, Interpellation, Post-Language Poetry, Kevin Davies

\section{Introduction}

Today, there are social processes at work in our historical moment that call into question the legitimacy of the legislators of the world, as pertains to American culture and its media that is presenting it. As of this writing, it's known that the National Security Administration is able to monitor phone records in this country, and that even Internet neutrality seems to be fading with President Obama's naming a chief lobbyist for media corporations as the head of the FCC. Literature might be one of the few forms of communication left to us that is unadulterated, and the codes that it uses to express itself and the codes it uses to interrogate other codes, now have a larger importance for cultural expression. Contemporary forms of poetry work to foreground the efficacy of these codes. As critic Lytle Shaw explained in his introduction to a reading by poet Kevin Davies, this work interrogates "what is actually said, to somehow what is imminent in what is said," in a way that often "conflat[es] world-historical and social scales... to picture the troubling and unpicturable processes at work" that influence communication through art and literature (Davies and Shaw) [1]. That is, through humor, Davies examines what is imminent in the phrases used by the Hegemonic order to expose the ways by which, as Shaw states, "efficient...human subjects are composed" in the social order, the way they are composed and inscribed into society through various Ideological State Apparatuses: the processes that censor, or otherwise restrict us into more manageable subjects.

For example, at least one of these unpicturable processes is interpellation. Davies gives voice to this process through the anti-rhetoricality of his poetry by locating his poetry within certain sites - namely those of the subject and its already-interpellated status, and within the English Composition Classroom. This contemporary poet's work uses unique forms of authorial presence in order to address and interrogate codes of social order and philosophical order. These include: a presence that undercuts its own authority to create rhetoric; a presence that engages in deliberate, sometimes ironic dynamics directly with the reader through codes; and a presence that engages in philosophical inquiries related to the performativity of the subject under constraint, mediations of capital, and the subject's recognition of its status as being interpellated in certain contexts. By examining authorial presence in the Language school, Davies' work in post-Language poetics can be situated within the frames of site-specificity, and poststructuralism, while revealing the limits of the subject in performing the acts of reading and writing.

\section{Authorial Presence and Post-Language Poetry}

A term I will be exploring in this thesis is "authorial presence." It has been used in some critical theory, but not with prevalence in the analysis of recent literature. Critic Hans Ulrich Gumbrecht wrote an entry on "presence" for 
the Princeton Encyclopedia of Poetry \& Poetics which casts some light on this concept. I propose to extend his statements to apply them to an understanding of the author as subject. Gumbrecht states, "Presence as expected and enjoyed by readers of poetry has a spatial more than a temporal dimension" (Greene et al. 1105) [2]. He goes on to connect this idea to poetic form: "Presence originates in what we call poetic form or artifice, e.g., in lines, rhyme, stanzas, and rhythm." Gumbrecht continues, stating:

We can define form as the simultaneity of self-reference and outside reference: a quadrangle, e.g., simultaneously points to itself and to the space outside itself. Once the space that defines the quadrangle starts moving, however, it becomes a time-object and, thus (unless this movement is sheer expansion or contraction), it no longer has the stability of a form. But a moving form can acquire such stability on a higher level if the sequence of changes that it runs through is recurrent, returning to the quadrangular form, e.g., then departing from it again in the same way it departed before, and so on. (Greene et al. 1105-06) [2]

Davies, especially in his award-winning book of poems, Comp., takes on the role of a poet-pedagogue in the cultural site of the English Composition classroom in order to analyze this role, and the role played by his students. Language poetry can be seen as, in the words of critic Barrett Watten, "a criticism of the adequacy of statement" (qtd. in Shaw 30) [3]. What we are looking for, though, is criticism of the adequacy of statement with regard to the author's social and/or artistic site. In this sense, what Davies does with this authorial presence is unprecedented. In the same way that Gumbrecht describes a form-in-rhythm as departing from and returning to a "space" in order to call attention to the dimensions of that space, Davies creates presence by taking on his subject-role of teacher, departing from it in formal moves to different subjective views, and then returning to his ground base of the pedagogue with reference to those previous formal moves. This is a presence that undercuts its own authority in order to call attention to the constraints imposed upon it, and the mediations of the power structures that determine the rules of rhetoric. As critic Christopher Nealon states about Davies, "Part of what it means to make an 'argument,' for Davies, is to make oneself legible in class-specific terms, in rhetorics that must be laboriously acquired, and whose acquisitions he experiences as an encounter with power" (158) [4]. Thus the content of each utterance in Davies, and the presences of authority that are foregrounded and then critiqued, illuminate certain social codes. Here is a short selection from Comp.:

Ridiculous

Landlocked miasma, let me get you a sweater.
Sentences

Are acceptable only insofar as they can be translated into Latin

with their meanings intact and confidence in empire unimpaired.

Never

Apologize, never send thank-you notes.

Persons

Atop the peak of your life, claiming it for England.

Curiosity

Pieces itself together between acts

of familial treachery, this is normal.[5]

The first stanza is an arresting address to nature, a kind of snide pathetic fallacy that is snide because of its obvious use of such a time-worn trope, finally indicated by the bathos of 'getting' it a sweater. Still, as one of the very few "pretty" utterances in the book, this playfully snide voice harkens back to the now-declared "lost" Romantic poet-persona. Davies, in recognizing and playing with this voice, articulates what such a Post-Romantic, yet Romantic persona would be like today. As David Levi-Strauss states (about Michael Palmer's persona), "This first person is trepidatious ... constantly undercutting its own authority" (qtd. in Perloff, "Language") [6]. We begin to see the consequence of this author-subject's process in this way as Davies moves from the poet persona back into the pedagogical mode.

The poem's next statement is similarly ironic, but takes on the role of a sort of speaker for the hegemon: sentences are "acceptable" (for the student's ambition of a good grade in the class) if they are directly connected to the empire and its language. The presence of the hegemon's influence is then personified and used to address its subjects and would-be heirs: when you're in power (or when you get to be thanks to your mastery of the Imperial language and code), don't show weakness by apologizing or showing gratitude. Next is an interrogation of this personification itself: even at your peak in this system, somehow "persons" (as opposed to the signaled-to difference of "people") will, in the end, claim your life for a different power (with England used humorously as the go-to code for non-Post-Colonial thinkers).

In the final move Davies returns to "himself," the professor. He turns back to a reassurance-through-irony that is similar to the valence of the first stanza. Yet woven into these rapid formal shifts is a short, foundational aphorism, found in the first line of each stanza: "Ridiculous ... Sentences ... Never ... Persons ... Curiosity" (Davies, Comp. 52) [5]. He mocks even the snide nature and irony of the first, "pretty," poetic stanza as being not enough for a poetic inquiry of a hyper-sensitive 
social space and climate. The merely "pretty," bruised Romanticism of the line is not enough to the poet-pedagogue; its use in the paratactic system of subjective interrogations (of subjects) must be viewed holistically via interrogation of the sequence as a whole. That is, the impulse to write itself is up for criticism.

\section{Kevin Davies and His "Sites"}

There is much at stake here in the arguments imminent in Davies' writing. William Lavender, in his essay, "Disappearance of Theory, Appearance of Praxis: Ron Silliman, $\mathrm{L}=\mathrm{A}=\mathrm{N}=\mathrm{G}=\mathrm{U}=\mathrm{A}=\mathrm{G}=\mathrm{E}$, and the Essay" offers a survey of the various literary and social currents that informed the praxis of the previous avant-garde, Language writing. Discussing Robert Greiner and his project, (illustrated by his famous declaration, "I HATE SPEECH") Lavender states, "The project is to take Williams a giant step further, to expand the "castigation" of archaic forms to a generalized linguistic negation, to condemn language in all its forms as the harbinger of the past" (191) [7]. As we have seen in the selection from Davies above, Davies' work depends on the unavoidable subjectivity found in linguistic utterances, often those of the past social order. His work employs paratactic examinations of speech acts coupled with other utterances of differing subjectivities. Davies shifts his subject positions to create this effect, and in doing so, undercuts his own authority, exposing it as already interpellated in nature, and this is due to the social sites Davies finds himself working from, such as the English Composition classroom.

Lavender acknowledges something similar in Grenier, stating that Grenier's is "a stance that works to make itself identifiable by difference. Thus it is that the renunciation of language can be prolix, like an actor falling in and out of character, oscillating between a theoretical negation and practical affirmation" (Lavender 191) [7]. Yet, as can be seen, this does not go far enough. Davies makes an identifiable difference through signaling to what is behind the speech/the phrases he uses and his intent for using it, these being different from what is the original intent. In this way, Davies is always perfectly "in character" as the author, not as an actor or in any other role so remote to the reader. As Davies himself states, "If it looks like a poem / it's a restraining order" (Davies and Shaw) [1]. The problems of structuralist difference will be addressed later in this paper, but for now, I will continue my focus on Davies specifically.

Language poetry has had this very problem of non-relation to the reader. As Jonathan Fedors states in his essay "Writing Class in Kevin Davies' Comp.," "Language poetics is premised on a structuralist homology between textual relations and social relations." [8] The solution to this problem is to simply delve farther into social relations by exploring oneself as mediated by capitalist structures of power, and more specifically, the author as already interpellated by power structures and codes. Davies therefore makes the content and rhetoric about those relations between author-and-self and author-and-reader with corresponding formal ingenuity. As Fedors states about these inventions, "Davies' work represents an evolution in the conceptualization of engaging with networks of ideology in social space, shifting the scale of formal disjunction from the level of language to the level of expressive subject, from grammar and syntax to voice and phrase." [8] In this case, the self can be viewed as yet another sign, and can thus be used in service of the poetic work of examining each code that is both called into the question by the author, and created by the author.

These problems are reworked by Davies to create an anti-rhetorical rhetoricality; this is one appropriate response to mediation and interpellation. Fedors refers to the arguments that Davies creates as rhetoric of "linguistic transparency." Paradoxically (but resulting in a work that avoids paradoxes) this work resists the urges of traditional rhetoric by calling attention to its own argumentative nature, but an argumentative nature that is fully aware of its own mediated status, given that many arguments refer to themselves as such. Again, we are looking for the 'adequacy of the statement' within certain sites. This is opposed to other forms, such as those of the Language writers, who seek to hide or even delete the rhetoric (the latter move being arguably impossible) that is always imminent in a writing guided by praxis. That is, any praxis, especially as named in a manifesto, contains rhetoric that cannot be ignored. Yet, some past writers working in this mode have tried to minimize this force in their writing. They have done this in the interest of making poetry that is a self-contained process of language without an authorial presence to direct its terms of reception. For example, much of Ron Silliman's oeuvre is questionable for its dependence on the body of criticism that Silliman produced. Silliman's poetry depends on his own rules. These rules set up simply a different site rather than the more inclusive one of social relations, the relations that is mediated by capital.

The author - especially through the signifiers he or she uses in the context of his or her presence and service to praxis - cannot be rendered "pure" of these mediations by linguistic work. Fedors defines the linguistic transparency of Davies in this way, "I mean a rhetorical anti-rhetoricality... Because materiality and poly-referentiality are incontrovertible aspects of the signifier, a claim otherwise - under the guise of 'forgetting' or evading them - is rhetorical."[8] In the case of my analysis, the author's presence can be taken as just another "signifier," and this conceptualization is in fact important for fully understanding Davies' project.

It is difficult to speak on different models of presence that can be observed as possible for authors, but again we may look to the Language poets whose legacy Davies 
draws on and modifies. One may see Language writers, especially from their origin in the work of Jack Spicer, as interested in forms that create an aesthetic meant to 'protect' poetry from encroachments of mass culture, rather than addressing them directly and changing the style of address to suit modes of inquiry. There is a difference between a production of poetry that is presumed to have value for its formal and aesthetic ingenuity, as in Silliman's The New Sentence, which examines the adequacy of the statement, and the production of poetry that addresses exchange value and inquiries into the adequacy of poetry. Critic Keston Sutherland, in his reading of Davies' Golden Age of Paraphernalia, recognizes this argument against old valuations of poetry within its formal inventions:

I . . . mean by "poetic values" the creditableness of technique, the currency as art of the manners and devices of expression traditionally proper to poetry ... all the distinguishing beauties of a poetic manifold whose labour of internal articulation is potentially infinite and whose analogies to anything at all in life or the universe can be at their most truthful when they are most immeasurably disproportionate. The Golden Age of Paraphernalia is evidently not a celebration of these famous distinguishing beauties or of the concept of the irreducibly poetic; its interest in the irreducible is as the optative conceptual chimera preceding the real thump of stupid social shrinkage. Poetic value in the form of the creditableness of technique is reasserted in The Golden Age of Paraphernalia as an innuendo for paranoiacs. (5) [9]

Sutherland quotes this passage from The Golden Age of Paraphernalia to show these poetic values being undercut. It shows authorial presence that recognizes poetic values, but undercuts its authority and power by exposing these values, as being, in his view, tricks that mimic the production of material for exchange:

The great negate. The final round

of adjudication and ridicule. For a time-say

thirteen thousand years - we were more or less always

giddy prospectors with claims on the attention of the invisible

archivist, and now look, no one can even get the cork out of the bottle intact. (Davies 54) [10]

Each line sets up a proposition that, in its enjambment, is undercut in the following line. This unstable presence is more than an unreliable narrator: Davies is a satirist against himself and his roles, making The New Sentence seem like a modernist trope engaged in connecting with some timeless, platonic, ideal form of consciousness that is just blindness toward poetic exchange values.

\section{Kevin Davies and Althusserian Interpellation}

The advantages to Davies' approach are numerous. Poets like Davies use the utterance as a tool to interrogate the social dynamics inherent in subjective views. That is, in Davies' case, the subject becomes a site of discourse in a way that is linked to larger issues, such as recognitions of the mediations of the subject's interpellated status. The subject can be the author, the author-as-writer, the author's audience, and/or the reader: all distinct and all interactions fruitful for interpretation within the discourse of social dynamics. In Comp., Davies finds himself as an author and teacher within the site of the English Composition classroom. Davies must recognize his language in a way that is hypersensitive to the many contributing factors to its creation. In this way, language itself can also be examined as a site. As Shaw states, there is "a turn, in avant-garde poetry of the 1970s and 1980s, away from empirical sites toward the idea of language itself as a site, so that the real would now become the linguistic (and therefore also the social and philosophical) preconditions for representation" (30) [3]. Yet Davies must recognize - astride the site of language - the site of the author's subject position in the context in which he works, whether it be physical or philosophical. The ideal-or simply the work-of representation then becomes fraught. As Michael Palmer states in an interview with Keith Tuma, "'Exploring the medium' is not in itself the goal. I hope we are questioning ways of understanding, seeing, and various crucial orders of assumption about meaning and representation in a culture where most things seem to have become re-presentation" (Palmer 9-10) [11]. The poet must be aware of his or her social contexts while responding to subjectivity. As Shaw states, "Self-reflexive moments . . . [can] no longer be separated from a would-be neutral process of accumulating material" (30) [3]. These self-reflexive moments in Davies' work underline the author's already-interpellated and mediated status.

Davies' work is geared toward not reflecting the social possibilities of our historical moment, but of transforming and disrupting them. We can turn to Comp. for a direct reference to this disruption. Davies uses his shifting subjectivity in this excerpt not to undercut his own authority as seen previously, but to use his authority as a social poet to disrupt conventionally-held modes of another authority and to highlight its absurdity:

Easier to just keep working that it ever is to stop.

\section{A flat tax.}

The noted social anthropologist. (Comp. 78) [5]

The first line is an utterance that is a recognizable social reality for many. The utterance is almost cliché because of this: capitalism seems to encourage and subsequently induce the condition of being a so-called "workaholic." 
Then, the statement is complicated by the existence of a seeming contradiction: no matter how hard one works, there will be taxes that will never coincide with one's degree of labor. At this point we begin to see the sort of system that works behind the scenes of the society demarcated, as well as the argument that is imminent in the codes of that system, which are never directly stated. Finally, in a pithy and deft gesture, Davies gives a name to the kind of employment that fits into this system, how and why the system rewards its laborers, and arguably exposes a flaw inherent in an entire department of academic study.

If anthropology is the study of different cultures by only one culture (call it a control culture), then it follows that the data resulting (provided that the research techniques follow certain formal rules and guidelines) should be data that is on "equal" ground with any other resulting data. How could one study's conclusions as pertains to an Indonesian people, for instance, be more lauded than another study of an Indonesian people? How could one social anthropologist gain more notoriety and funding from his or her control culture than another? The answer, as Davies implies, is that the control culture stands to economically benefit more from that social anthropologist's conclusions: the rulers of the control culture can use the data to bring the studied culture under its influence, much as it does to its own citizens with its flat taxes and encouragement of horizonless labor despite those taxes. The stance may strike one as pessimistic, but its anti-colonial grounding has a precedent in our current historical moment.

The field of social anthropology, and its related field (arguably an evolution of social anthropology), social psychology, saw a call for dramatic reorganization in 2010. Former anthropologist Joe Heinrich, later working with social psychologists Steven Heine and Ara Norenzayan, published a landmark paper titled "The Weirdest People in the World?" (this paper is discussed in Ethan Watters' article for Pacific Standard Magazine titled "We Aren't the World"). They argued that anthropological researchers, for decades, had used only a small subject population to apply study conclusions to the population of the world. That small population, they deemed as Western, Educated, Industrialized, Rich, and Democratic (WEIRD). They found that, in essence, almost all of the anthropological work of previous researchers should be called into question, at the very least, and, ideally, it should be summarily thrown out in the name of scientific procedure (Watters) [12]. As Ethan Watters summarized the illogical and damaging procedures of past researchers:

Economists and psychologists, for their part, did an end run around the issue with the convenient assumption that their job was to study the human mind stripped of culture. The human brain is genetically comparable around the globe, it was agreed, so human hardwiring for much behavior, perception, and cognition should be similarly universal. No need, in that case, to look beyond the convenient population of undergraduates for test subjects. [12]

Heine and his peers found hugely disparate forms of cognition among cultures when they went against the grain and actually used test subjects from cultures to which their research would presumably apply. Davies' simple use of the adjective "noted" before "social anthropologist" in the context of his interrogation of social codes (and this back in 2000) recognizes the conflicts of our contemporary moment with the vestiges of colonialism (Comp. 78) [5].

This is a form of resistance against the rules themselves. Cast in the terms of Shelley's statement that poets are the "legislators (via mastery of language), Davies presents the rules necessary for completing his work, and in so doing shows that these rules are not arbitrary (here we can think again of Language poetry's numerous rules in limiting its context, its insistence to be read by its own rules). As Wiens states:

Davies does not simply shift the authority of productive locus of meaning to the reader in the spirit of poststructuralism or early $\mathrm{L}=\mathrm{A}=\mathrm{N}=\mathrm{G}=\mathrm{U}=\mathrm{A}=\mathrm{G}=\mathrm{E}$ texts: rather both subject positions (of writer and of reader) are betrayed as overdetermined. The brackets in this sense enact or perform a critique of property relations more explicitly stated at various places in the book ("You have my permission to sleep on my porch" [501]) by undermining the position of author (or reader) as either original source or empowered selector of meanings. (194) [13]

Yet we may even take this proposition further: Davies uses his control of the text to illustrate the rules by which he exercises that control. Davies offers a direct explanation of this aim in Comp., where he breaks down the rules by which not only his text is to be received, but the rules of communication and reception of texts themselves:

I learned the year after kindergarten that sentences are linguistic artifacts with regulations that fill themselves out, and that for the purpose of our circus-cannon

ambitions the most important part of the war they enact

is the full-stopping dots that divide the booty amongst

camp-following berserkers of the sub-syllabic frontier. (33) [5]

If sentences contain "regulations that fill themselves out" (Davies, Comp. 33) [5], what does this mean in terms of a subject in a work of poetry? Arguably, Davies takes the position that the limits of a subject mark themselves as well, based as they are on the medium of language. The work of 
site specificity not only means finding or creating a site, of course, but also includes determining the limits of that site, and interrogating why those limits exist and what they indicate.

This is a difficult proposition, but one may find grounding of the concept in the continuing social criticism that Davies performs. Davies' work does not enact a sort of Althusserian interpellation that this concept might imply, but rather a consolidated call for recognition on the reader's part, with the author's shared responsibility, of the interpellation that has already been brought upon the subject sometime prior (Althusser actually emphasized that the subject was already interpellated). This is exactly what drives Davies to undercut his own authority, and is part of his 'anti-rhetorical rhetoricality.' Again, as Nealon states, Davies makes his arguments by "making [him] self-legible in class-specific terms, in rhetorics that must be laboriously acquired, and whose acquisitions he experiences as an encounter with power" (158) [4]. Davies, then, foregrounds the power of rhetoric he has learned by undercutting his own authority as a wielder of that. This move essentially calls attention to the absurdity of the basis of this power, and foregrounds his interpellated status in even presuming to expose these power relations:

\section{The consolation of a rich \\ outer life, accentuated, made \\ poignant by, a government- \\ sponsored sleep-deprivation \\ program integrated with \\ the consolidation of stray facts \\ into fully erect}

adult earning power, gated and patrolled.

quotable thought sequence

If we doubted our function

we'd immediately go out. But (Davies, Comp. 38) [5]

The last two lines are especially telling. The rules of a society dictated by ideology do not include allowance for the subject to doubt his or her function. This function is tied up with "stray" facts: those facts that do not have a natural home, but should, if one is true to his or her function. The assonance of "consolation" with "consolidated" further points to what force it is that is gathering these facts into the "adult earning power" that produces the "rich outer life" (Davies, Comp. 38) [5].

We can take "quotable thought sequence" to be an interrogation of these social codes (which are made present by the author himself). Yet it is also one of a few moments in Comp. where Davies performs at once a self-referential utterance, a kind of place holder for what should be there (Davies as the author should provide this formal structure here), as well a sort of guess as to what the reader would be thinking. This happens earlier in the book in a similar manner: "sequential thought quota" (Davies, Comp. 9) [5]. These moves signal toward the subjectivity of language and the objectivity of the subjects, both author and reader. This aim for Davies has grounding in contemporary readings of Marx, which have been aimed toward reversing many of the binaries he proposed.

The reading and writing subject's understanding of his or her own limits under ideology must be continually reified through enacting and reading presence, but the struggle to do so is endless. Davies makes subtle allusion to all this in Comp., recognizing the perhaps inability to mark these boundaries at this juncture: "We'll look back years from now and recognize the mannerism for what's opaque of its method" (65).

\section{Conclusions}

Through his use of authorial presence, Davies makes codes that interrogate the social codes that inscribe us in ideology. This presence is one that enters into a degree of engagement with its status as mediated and interpellated, which cannot be found in the authorial presences of the Language poets. Through this act, he places his work in the site of language more fully than previous writers, marking the site's limits and philosophically probing toward why these limits exist. He arrives at an issue of subjects and objects enacted by language, and responds with poetic disproportion within this site to mark their boundaries. To accomplish this inquiry, he reverses the binary of subject and object, and constructs his codes from this new conception of presences enacted within the site of language. The subject is given a new anthropological importance, and is anatomized within new Marxist readings of the performativity of the producing and accumulating artist and reader. This new anthropological importance is that which marks the author as already interpellated, and one who resists the currents of universalism and plurality. This process gives rise toward new understandings of the produced material at hand: the consequences of interpellation that are to be found in readings of the available language, and new readings of poststructuralist-responsive writing.

The key to engaging with Davies' work might be found through one of the quotes that opens this paper: Shaw's introduction to one of Davies' readings. Shaw states that Davies' work interrogates "what is actually said, to somehow what is imminent in what is said," in a way that often "conflat[es] world-historical and social scales . . . to picture the troubling and unpicturable processes at work" that inscribe us in ideology. Davies' work represents these processes and forces us to live with them, since "we already are [living with them]" (Davies and Shaw)[1]. Shaw states that Davies' social humor is what points to 
these processes. Like any skilled humorist, the laughter or introspection that results from a good joke is not so much a result of what is actually said, but what the joke points to: often the listener's identification with the speaker of a shared grievance or an identification of the absurd circumstances that make the joke and laughter possible.

Shaw explains that Davies seeks "To explore the linguistic forms and social processes by which efficient, docile human subjects are composed" [1]. So what is stake in Davies' humor might be found in concepts of cultural hegemony. Gramsci's concept of Cultural Hegemony is perfectly understandable as theory, but when it comes to individuals' interpretations of it, or rather, pointing to instances of Cultural Hegemony's effects in society, it becomes very difficult. It is especially difficult in Davies' writing which explores "the phrase as...a tool" of the hegemonic order. Some humorous lines from The Golden Age of Paraphernalia might assist. Davies writes, "A finger, an entire / arm / pointing to a moon / in a puddle / in a mirror - / say something" [10]. The lines cite the old Buddhist adage that art and poetry is the manifestation of a finger pointing at the moon: art is the apparatus by which one gains a different perspective of the moon, of natural beauty. The humor here uses irony to state that the Ideological State Apparatuses of Cultural Hegemony have occluded the moon. It now takes an entire arm to point, and the Ideological clouding has obstructed direct access to natural beauty: it cannot be seen directly, but through a "puddle" itself reflected "in a mirror" [10]. It is as difficult to point at the moon as it to point at the Ideological processes which obstruct one's seeing their causes and effects: they are puddles and mirrors, and all manners of interfering apparatuses. Yet, we have to continue to "say something", to work towards exposing the means by which we are restricted.

\section{REFERENCES}

[1] Davies, Kevin, and Lytle Shaw. The Line Reading Series. The Drawing Center, New York. 22 May 2001. Reading. Pennsound, Web. 12 Aug. 2014.

[2] Greene, Roland, et al., eds. The Princeton Encyclopedia of Poetry and Poetics. 4th ed. Princeton: Princeton UP, 2012. Print.

[3] Shaw, Lytle. "Docents of Discourse: The Logic of Dispersed Sites." American Poetry After 1975. Spec. Issue of Boundary 236.3 (2009): 25-47. JSTOR. Web. 12 Aug. 2014.

[4] Nealon, Christopher S. The Matter of Capital Poetry and Crisis in the American Century. Cambridge, MA: Harvard UP, 2011. Print.

[5] Davies, Kevin. Comp. Washington, D.C.: Edge, 2000. Print.

[6] Perloff, Marjorie "Toward a Wittgensteinian Poetics." American Poetry of the 1980s. Spec. Issue of Contemporary Literature 33.2 (1992): 191-213. JSTOR. Web. 12 Aug. 2014.

[7] Lavender, William. "Disappearance of Theory, Appearance of Praxis: Ron Silliman, $\mathrm{L}=\mathrm{A}=\mathrm{N}=\mathrm{G}=\mathrm{U}=\mathrm{A}=\mathrm{G}=\mathrm{E}$, and the Essay." Poetics Today 17.2 (1996): 181-202. JSTOR. Web. 12 Aug. 2014.

[8] Fedors, Jonathan. "Writing Class in Kevin Davies' Comp." Jacket2. N.p., Oct. 2006. Web. 12 Aug. 2014.

[9] Sutherland, Keston. "Poetry and 'Monstrous Accumulation'." 2014. TS. U of Sussex, England.

[10] Davies, Kevin. The Golden Age of Paraphernalia. Washington, D.C: Edge, 2008. Print.

[11] Palmer, Michael. Interview by Keith Tuma. "An Interview with Michael Palmer." Contemporary Literature, 30.1 (1989): 1-12. JSTOR. Web. 12 Aug. 2014.

[12] Watters, Ethan. "We Aren't the World." Pacific Standard. Miller-McCune, 25 Feb. 2013. Web. 12 Aug. 2014.

[13] Wiens, Jason. "The Kootenay School of Writing: History, Community, Poetics." Nq64891.pdf. University of Calgary, Sept. 2001. Web. 